\title{
Can mandible morphology help predict feeding habits in Antarctic amphipods?
}

\author{
LOÏC N. MICHEL (1) $1,2,3, \dagger$, FABIENNE L. NYSSEN ${ }^{1, \dagger}$, PATRICK DAUBY (i) ${ }^{1}$ and MARIE VERHEYE (i) 2 \\ ${ }^{1}$ Laboratory of Systematics and Animal Diversity, Freshwater and Oceanic Sciences Unit of reSearch (FOCUS), University of Liège, \\ 4000 Liège, Belgium \\ ${ }^{2}$ Laboratory of Oceanology, Freshwater and Oceanic Sciences Unit of reSearch (FOCUS), University of Liège, 4000 Liège, Belgium \\ ${ }^{3}$ Current address: Ifremer, Centre de Bretagne, REM/EEP, Laboratoire Environnement Profond, F-29280 Plouzané, France \\ loicnmichel@gmail.com \\ ${ }^{\dagger}$ These authors contributed equally to the manuscript and are co-first authors
}

\begin{abstract}
In Antarctica, amphipods form a highly diverse group, occupy many different ecological niches and hold an important place in food webs. Here, we aimed to test whether differences in Antarctic amphipod feeding habits were reflected in their mandible morphology, and if mouthpart specialization could be used to describe amphipod trophic ecology. To do so, we compared mandible morphology in nine species spanning seven families and five functional groups (grazers, suspension feeders, generalist predators, specialist predators and scavengers). Mandible morphology adequately depicted some aspects of amphipod trophic ecology, such as the trophic level at which animals feed or their degree of dietary specialization. On the other hand, links between mandible morphology and amphipod diet were seldom unambiguous or straightforward. Similar adaptations were found in distinct functional groups. Conversely, mandible morphology could vary within a single functional group, and phylogenetic effects sometimes complicated the interpretation of form-function relationships. Overall, mandible morphology on its own was generally not sufficient to precisely predict amphipod feeding strategies. However, when combined with other methods (e.g. gut contents, trophic markers), it constitutes a valuable source of information for integrative studies of amphipod ecological diversity in the Southern Ocean.
\end{abstract}

Received 3 April 2020, accepted 31 May 2020

Key words: diet analysis, food webs, Peracarida, scanning electron microscopy, Southern Ocean, trophic ecology

\section{Introduction}

In Antarctic shelf ecosystems, Amphipoda constitutes, despite its relatively low biomass, a significant group in terms of energy flux (Dauby et al. 2001b, 2003). These crustaceans are among the most diversified Antarctic benthic taxa with respect to number of species, lifestyles, habitats and size spectra (Watling \& Thurston 1989, Momo et al. 1998, De Broyer \& Jażdżewska 2014). As the group is highly diverse, one would expect amphipods to occupy an important number of different ecological niches to exploit the full spectrum of resources. Previous work based on gut content examination and trophic markers has accordingly shown that Antarctic amphipods exhibit high trophic diversity and cover a wide range of consumed preys, feeding behaviours and eco-functional roles (Dauby et al. 2001a, 2001b, Graeve et al. 2001, Nyssen et al. 2002, 2005). Adaptation to a wide variety of ecological niches should be reflected in the diversity of functional morphological traits. Changes in mouthpart morphology, and particularly in mandible anatomy, have notably been interpreted as adaptations to presumed preferred food sources (Momo et al. 1998, Watling 1993).

In amphipods, the mandible serves both for cutting and grinding (crushing) food (Manton 1977). It consists of four main structures (Fig. 1), starting distally and going to the mouth opening: the incisor process, a projection of the mandibular body that sometimes bear cusps or teeth; the lacinia mobilis, an articulated and sometimes toothed plate inserted close to and generally in line with the incisor; the seta row, filling the space between incisor and molar and presumably preventing food particles from falling away from the molar; and the molar process, a columnar structure projecting from the mandibular body and often provided with multiple triturative surfaces (Fig. 1) (Watling 1993). In typical peracarid biting, the left and right mandibles have distinct roles. The right incisor process enters the gap between the left incisor and the left lacinia mobilis, which glides into the gap left between the right incisor and the right lacinia, when the latter is present. The lacinia mobilis contributes to cutting and helps to guide the incisor processes into the right planes and to lock 


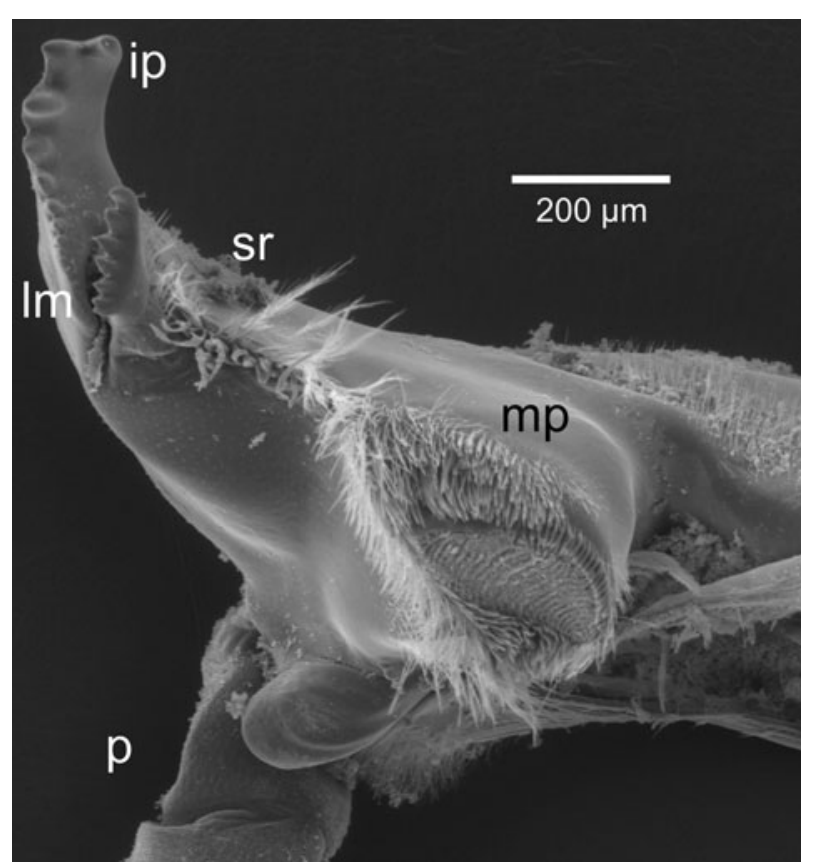

Fig. 1. Structure of a typical gammaridean amphipod mandible. $\mathrm{ip}=$ incisor process, $\mathrm{mp}=$ molar process, $1 \mathrm{~m}=$ lacinia mobilis, $\mathrm{p}=$ mandibular palp, $\mathrm{sr}=$ setae row.

them into their final closing position. In addition, a toothed or spiny lacinia mobilis probably helps to hold food particles in place during the bite (Dahl \& Hessler 1982, Watling 1993). Due to their different roles in feeding, asymmetry between the left and right mandibles is commonly observed in amphipods. The left lacinia mobilis, notably, is often larger, stronger and/or bears more ornamentation than the right one (Watling 1993, Mayer et al. 2013). Besides this, a large panel of modifications to the abovementioned typical mandible morphology pattern can be observed among amphipods. They include reduction or overgrowth of the incisor process, disappearance of the setae row and reduction or complete loss of the molar process (Watling 1993).

Many studies have suggested associations between specific mouthpart morphologies and feeding strategies (Coleman 1989a, 1989b, 1990, Arndt et al. 2005, Mayer et al. 2009, Mekhanikova 2010, Pavesi \& Olesen 2017). The 'basic' amphipod morphology, observed in most gammaridean families, is typically associated with detritivory and with suspension and/or deposit feeding. The compact mandible body bears a toothed incisor, a well-developed and toothed lacinia mobilis and a columnar molar, designed for crushing (Watling 1993). Filter-feeders often combine this basic mandible morphology with increased mouthpart setation (Caine 1974, Cole \& Watkins 1977, Mayer et al. 2009). Detritus feeders, which primarily feed by processing benthic sediments or biofilms, have proportionally larger and more strongly dentate mandibles and increased molar grinding surfaces, suggesting an adaptation to mastication. Moreover, they have teeth and cuspidate setae on maxillae and maxillipeds for scraping off adherent food from substrates (Caine 1974, Coleman 1991, Arndt et al. 2005, Mayer et al. 2009). Enlarged, strong, toothless and sharp incisors are generally associated with increasingly predatory feeding habits (Coleman 1990, Haro-Garay 2003, Guerra-García \& Tierno de Figueroa 2009, Hutchins et al. 2014). Predators feeding on relatively soft prey (e.g. some cnidarians, sponges, holothurians or polychaetes) appear to share an absent or greatly reduced molar (Coleman 1989a, 1989b, 1990, Watling 1993, Guerra-García \& Tierno de Figueroa 2009), whereas a broader and triturative molar is presumably used to crush more rigid food items, such as crustacean exoskeletons (Caine 1974, Sainte-Marie 1984, Haro-Garay 2003). Highly adapted scavenger species generally combine wide, sharp and toothless shearing incisors (to bite off large pieces of carrion) with tall, conical, posteriorly projecting, non-triturative molars, which push pieces of food into the stomodeum without chewing (Dahl 1979, Sainte-Marie 1984, Steele \& Steele 1993, Watling 1993, Arndt et al. 2005, Seefeldt et al. 2017). Facultative scavengers often show some degree of omnivory and appear to have a somewhat distinct mandible morphology compared to exclusive scavengers, characterized by a slender incisor and a lower triturative molar process (Dahl 1979, Momo et al. 1998, Arndt et al. 2005, Seefeldt et al. 2017). Finally, herbivorous habits are generally associated with sturdy and sharp incisors combined with wide and highly structured (rasp-like) molars, as this mandible morphology is well-suited for cutting and grinding firm plant material (Watling 1993, Mayer et al. 2009, Pavesi \& Olesen 2017).

Overall, amphipod mouthpart morphology seems to be correlated with their trophic ecology. However, the functional significance of many morphological traits or modified structures in amphipods is still incompletely understood. Here, we aimed to test whether differences in feeding habits were reflected in the morphology of the mandible in multiple Antarctic amphipod groups. To do this, we examined mandible morphology in nine species spanning seven families and five functional groups (grazers, suspension feeders, generalist predators, specialist predators and scavengers) (Table I) and related our findings to available information on their feeding ecology (generated by gut content analyses, stables isotopes and fatty acid trophic markers). We hypothesized that mandible morphology and feeding habits would be closely related and that the mandible should show strong morphological differences between species belonging to different functional groups or having different feeding habits, while the mouthparts of species showing similar feeding habits would bear more resemblance. 
Table I. Families, functional groups (according to literature), sampling locations and specimen sizes for the nine studied amphipod species.

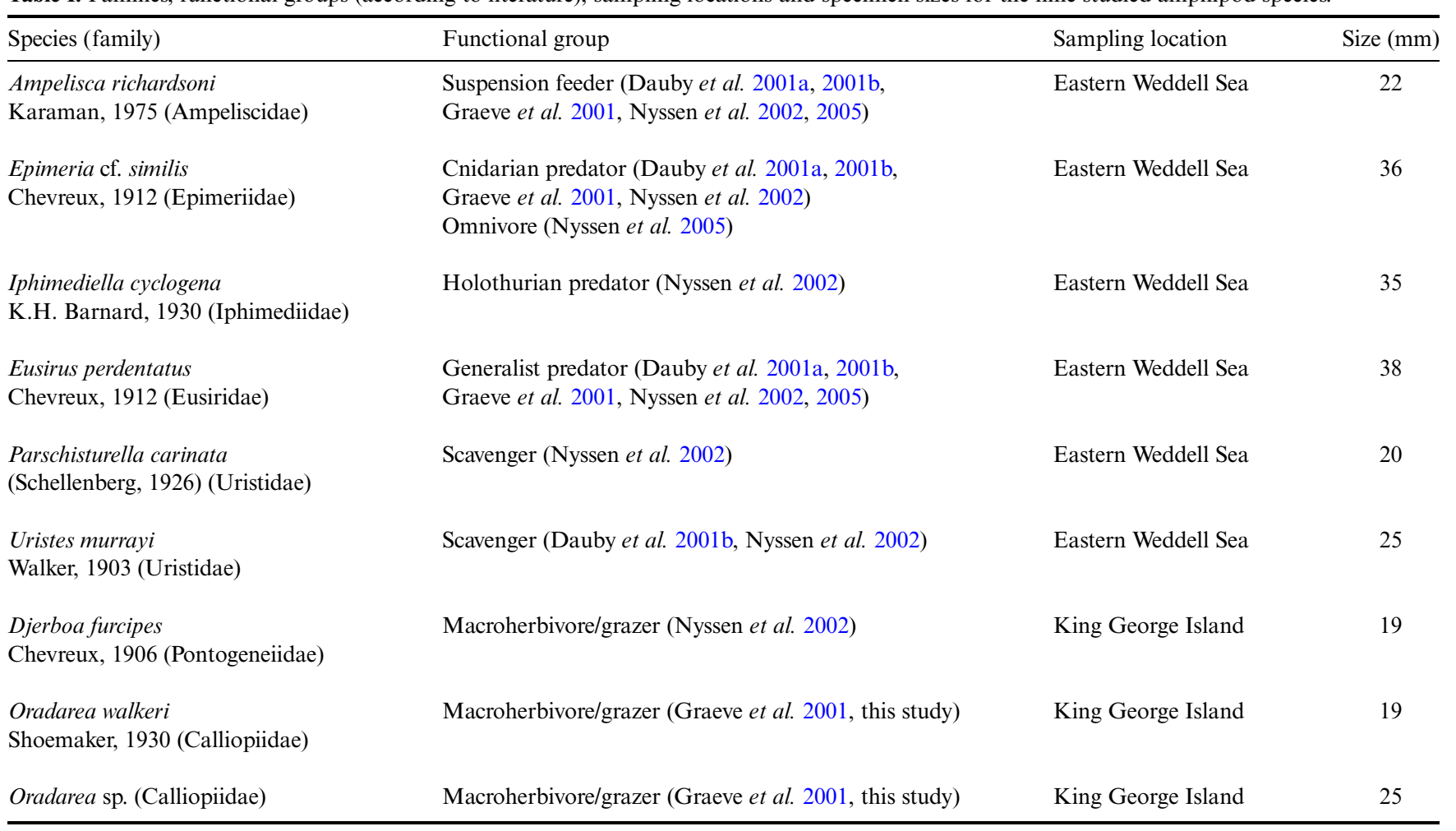

\section{Material and methods}

Specimens of six species (Table I) were collected with Agassiz, benthopelagic and bottom trawls and dredges in the eastern Weddell Sea during three Antarctic summer cruises of RV Polarstern: EPOS leg 3 (1989), EASIZ I (1996) and EASIZ II (1998). Individuals of Oradarea walkeri and Djerboa furcipes were sampled on King George Island (South Shetland Islands, Antarctic Peninsula) in 1993. They were either hand-collected in the upper part of the infra-littoral of Admiralty Bay during spring tides or dredged in shallow water in the vicinity of the Henryk Arctowski Polish Antarctic station during the summer season. Finally, the Oradarea spp. were also collected on King George Island during the summer of 1993, but at depths of $400 \mathrm{~m}$ using traps baited with different macroalgae (Desmarestia menziesii or Iridaea sp.).

For each species, a single adult (see body sizes in Table I) female specimen was selected for mouthpart morphology examination. Animals preserved in 10\% formalin were dissected under a binocular microscope (Leica MZ12) using forceps and scissors. After dissection, amphipod mandibles were dehydrated through an alcohol series, critical point-dried and then sputter-coated with carbon then gold to be observed by scanning electron microscopy.

To assess congruence between mouthpart specialization and feeding habits, mandible morphology was compared to trophic ecology as depicted by feeding behaviour observations, gut content analyses and trophic markers (stable isotope ratios, lipid and/or fatty acid analyses). Gut content data for Ampelisca richardsoni, D. furcipes, Epimeria cf. similis, Eusirus perdentatus, Iphimediella cyclogena, Parschisturella carinata and Uristes murrayi were extracted from the literature (Dauby et al. 2001a, 2001b, Graeve et al. 2001, Nyssen et al. 2002, Aumack et al. 2017). As, at the time the study was performed, no gut content data were available for $O$. walkeri, Oradarea sp. or D. furcipes, they were analysed for this study. For 20 specimens of each species, the digestive tract was cut at the oesophagus level and removed together with the midgut glands. It was then separated from the midgut glands, opened, and its contents were spread on a microscope slide. Slides were examined under an optical microscope (Leica DMLB equipped with a reflection contrast system). Feeding behaviour observations were taken from Klages \& Gutt (1990) and Dauby et al. (2001a); stable isotope ratios analyses were taken from Nyssen et al. $(2002,2005)$ and Aumack et al. (2017); and lipid and/or fatty acid composition analyses were taken from Graeve et al. (2001) and Nyssen et al. (2005) and Aumack et al. (2017). As no trophic marker measurements were, to the best of our knowledge, available for Oradarea sp. or O. walkeri, we compared their mandible morphology with results obtained on their congeners Oradarea edentata (Graeve et al. 2001) and Oradarea bidentata (Aumack et al. 2017). 

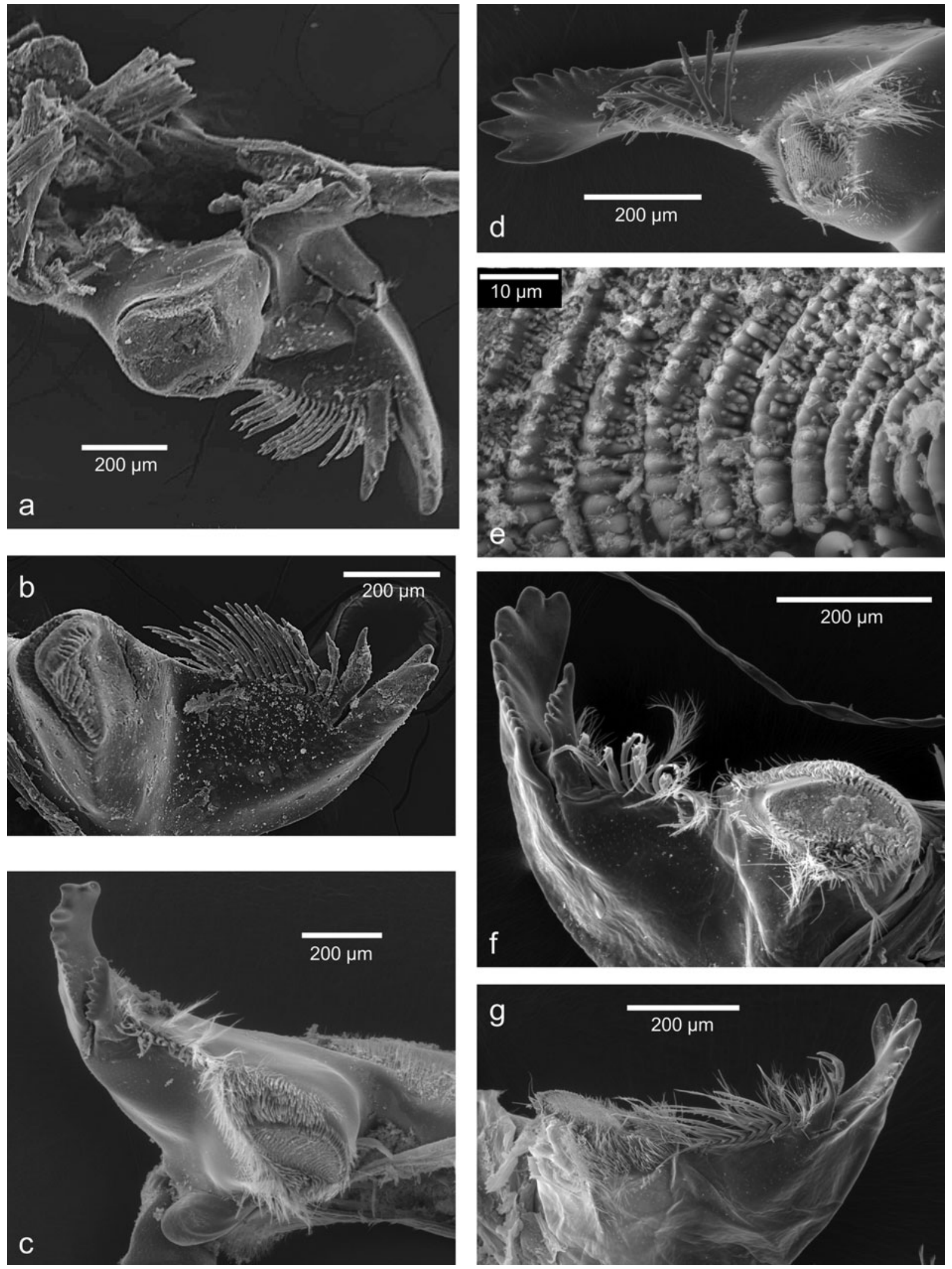

Fig. 2. Scanning electron micrographs of the mandibles of the studied amphipods (primary consumers). a. Ampelisca richardsoni, left mandible. b. Ampelisca richardsoni, right mandible. c. Oradarea sp., left mandible. d. Oradarea sp., right mandible. e. Oradarea sp., details of molar process. f. Oradarea walkeri, left mandible. g. Djerboa furcipes, left mandible. 


\section{Results}

Both mandibles of $A$. richardsoni (Fig. 2a \& b) bore well-developed incisors and molar processes. Both incisors presented five rounded cusps, and the left one (Fig. 2a) was ornamented by a strong five-toothed lacinia mobilis. The right lacinia mobilis was smaller and more spine-like (Fig. 2b). The molars were prominent and some smooth ridges were visible. The most striking feature of those mandibles was the development of the setae rows: on both sides, the row was composed of $\sim 15$ serrate setae nearly as long as the lacinia mobilis.

The gut composition of Oradarea sp. depended drastically on the used macroalgal baits. When they were made of pieces of the brown algae Desmarestia menziesii, 95\% of the gut volume was filled with fragments of this algae. On the other hand, when baits consisted of pieces of Iridaea sp., the gut content was composed of mineral particles, of frustules of different kind of diatoms, of chitinous structures and, in some specimens, of a small number of pieces of Iridaea sp. Mandibles were asymmetrical regarding the morphology of the lacinia mobilis (Fig. 2c \& d). The incisor bore ten rounded cusps. The left lacinia (Fig. 2c) was similar to the incisor, but smaller and with only seven more acute cusps. The right lacinia (Fig. 2d) was slender. The setae row consisted only of stout serrate setae (Fig. 2d) on the right mandible, while an additional parallel row of plumose slender setae was present on the left mandible (Fig. 2c). The molar process was massive and sub-columnar, and the triturative area was closely surrounded by short and thick setae and topped by a dense crown of setae. The grinding surface of the molar process was provided with densely set short spinules and ridges with serrate distal margins (Fig. 2e).

A total of $90 \%$ of the gut contents of $O$. walkeri were composed of pieces of macroalgae. The other $10 \%$ consisted of different types of diatoms and of inorganic material. Mandible morphology was nearly identical to that described for the other Oradarea sp. (Fig. 2f). Both incisors were well-developed and bore ten strong teeth. The rather flat mandibular body was bordered ventrally by a double row of stout serrate setae and by slender plumose setae. The large and tall molars were topped by a dense fringe of setae and bore a large triturative area provided with ridges and other rasp-like structures. Both mandibles were flanked by a lacinia mobilis, which was strong and seven-toothed on the left mandible (Fig. 2f) and weaker and spine-like on the right mandible (not shown).

Examination of the gut contents of $D$. furcipes revealed that they were composed of more than $85 \%$ of pieces of macroalgae, $10 \%$ of pennate diatoms and a small amount of chitinous parts. All dissected specimens also had mineral particles in their guts. As with both species of the genus Oradarea, D. furcipes displayed basic gammaridean amphipod mandibles (Fig. 2g). They had ten-toothed incisors, a left lacinia mobilis with ten teeth, but only three on the right one (Fig. 2g), large (yet smaller than in the genus Oradarea) cylindrical and triturative molars crowned by a dense fringe of small setae and the setae row, like in $O$. walkeri, was composed of two different types of setae (plumose and serrate).

Both mandibles of $E$. cf. similis (Fig. 3a \& b) bore strong ten-toothed incisors and tall sub-columnar molars provided with well-developed and smooth ridges. The molars were surrounded by a row of stubby setae and fringed with bundles of hair-like setae at their dorsal margin. The left lacinia mobilis (Fig. 3a) was armed with seven cusps, whereas the right one was smaller, bifurcated and spine-like (Fig. 3b). The setae row was composed of stout denticulate setae, flanked on the ventral side by slender setae.

The mandibular body of I. cyclogena was elongate, tapering into the incisor that was much narrower than in all other species considered in this work (Fig. 3c). Both incisor processes were toothed (ten cusps) and bore a long lacinia mobilis that was inserted close to the molar process, which was reduced to a small fleshy cone. The left lacinia mobilis (Fig. 3c) was thick and strongly chitinized, but the right one (Fig. 3d) was reduced to a thinner, twig-like structure. A major modification was the change in the orientation of the incisor, cutting in the vertical frontal plane.

The mandibles of E. perdentatus bore strong incisors and molar processes (Fig. 3e). The incisor was wide and smooth, flanked by a single cusp at each end. The left lacinia mobilis was denticulated and seven-toothed (Fig. 3e), whereas the right one was armed with just two teeth. The short setae row was composed of approximately ten setae. The apex of the tall sub-columnar molar bore a small triturative area with rasp-like structures (Fig. 3f).

The proximal parts of the incisors of $U$. murrayi incisors were narrow, and the structures broadened distally (Fig. 4a). The cutting edge was smooth and flanked by a single cusp at each end. The lacinia mobilis was present on both mandibles. The setae row was composed of three setae, followed by a dense string of hairy setae bordering the mandibular body. The molar was oval-shaped and surrounded by a ventral fringe of setae that partly overlapped the relatively smooth triturative area (Fig. 4a).

The incisor processes of $P$. carinata were smooth, and their edges were rather sharp and flanked by a single cusp at each end (Fig. 4b). The slightly concave mandibular body was bordered by a row of seven or eight thick setae. The left mandible bore a weak digitiform, apically bidentated lacinia mobilis (Fig. 4b). The molars were tall and ornamented with setae. The oval triturative area bore several series of deeply toothed ridges and rasp-like structures and was more developed than in $U$. murrayi (Fig. 4c). 

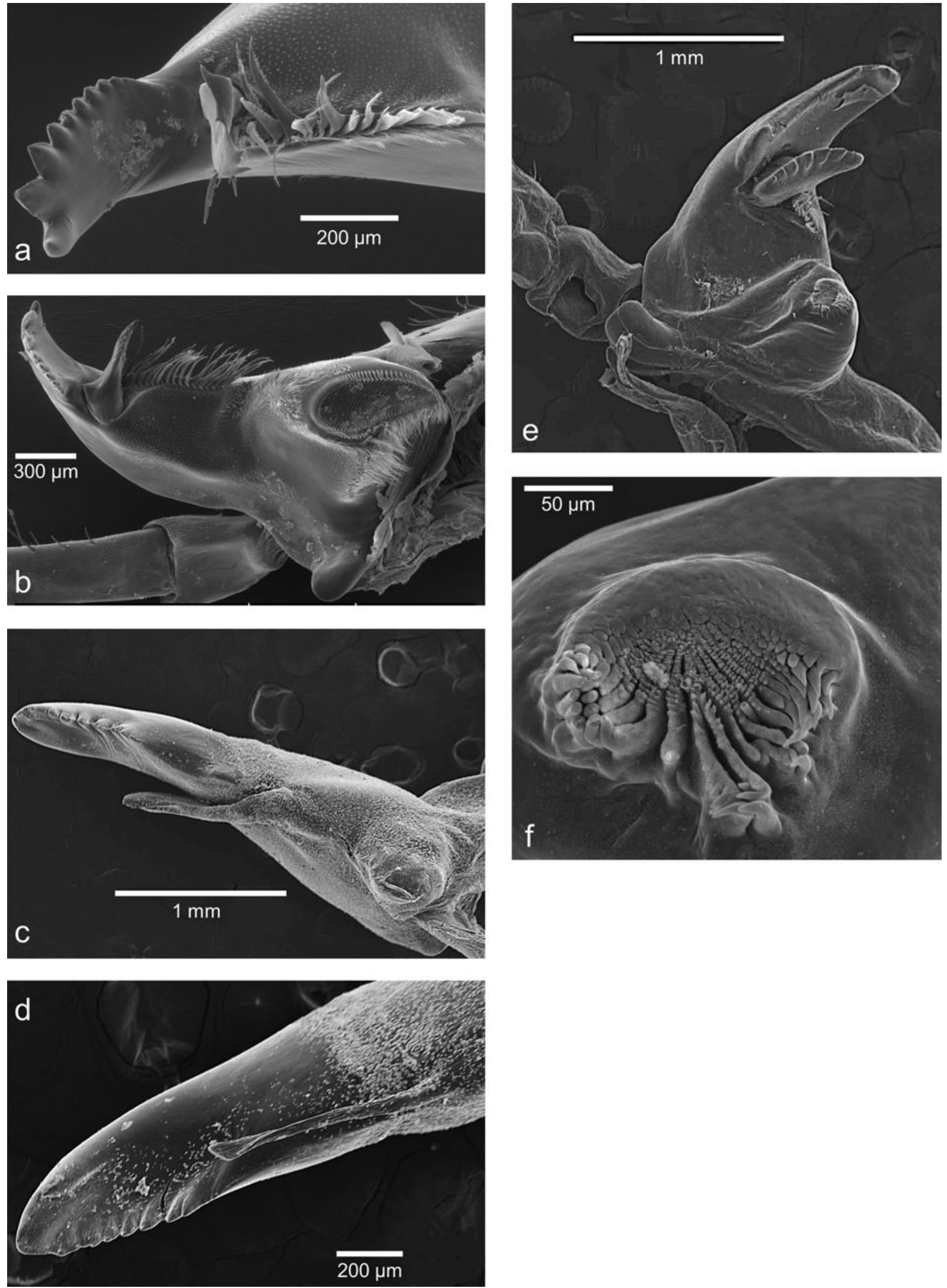

Fig. 3. Scanning electron micrographs of the mandibles of the studied amphipods (predators). a. Epimeria cf. similis, left mandible. b. Epimeria cf. similis, right mandible. c. Iphimediella cyclogena, left mandible. d. Iphimediella cyclogena, details of right lacinia mobilis. e. Eusirus perdentatus, left mandible. f. Eusirus perdentatus, details of molar process. 

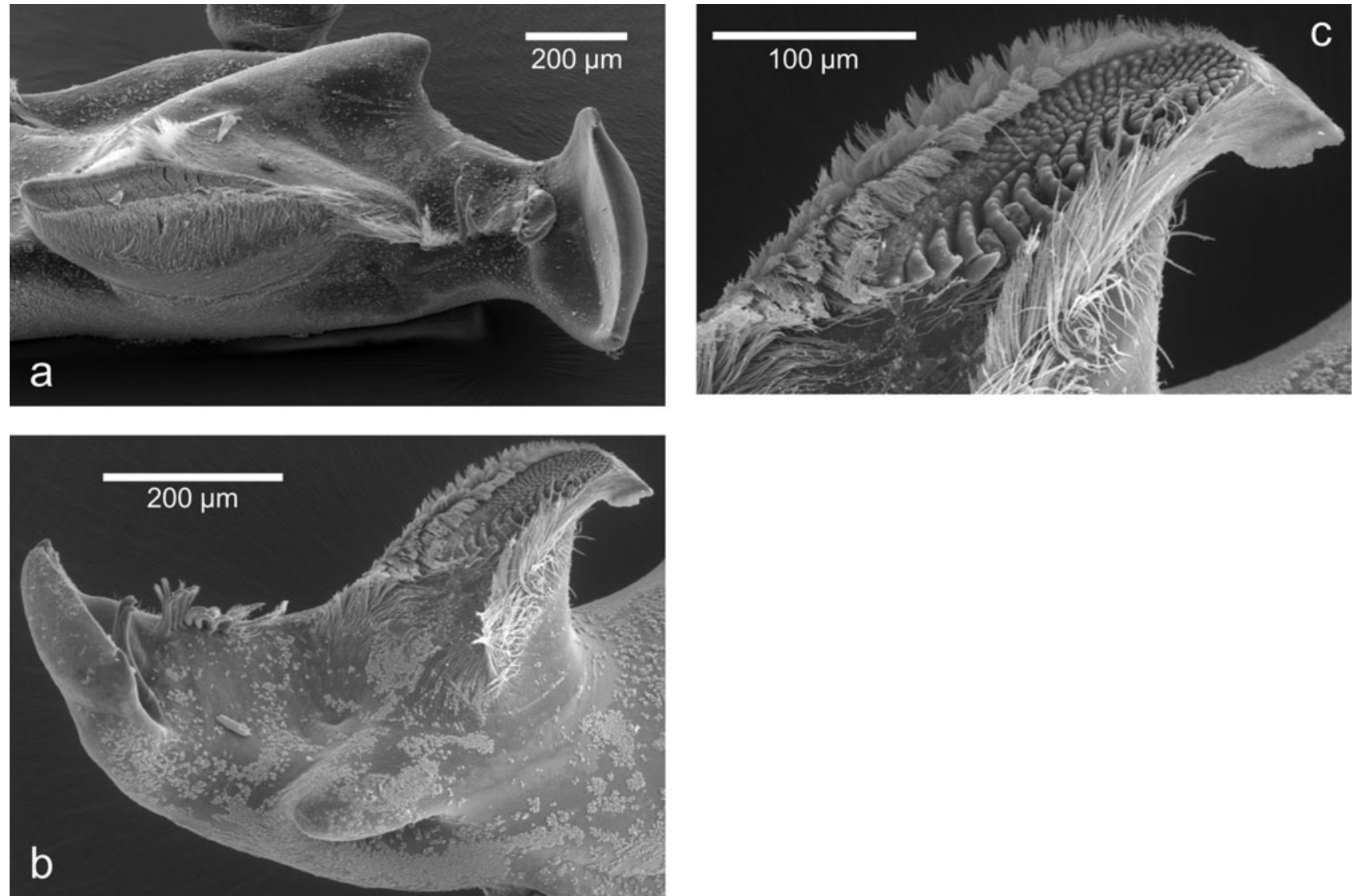

Fig. 4. Scanning electron micrographs of the mandibles of the studied amphipods (scavengers). a. Uristes murrayi, right mandible.

b. Parschisturella carinata, left mandible. c. Parschisturella carinata, details of molar process.

\section{Discussion}

\section{Macroherbivores/grazers}

While our study is, to the best of our knowledge, the first one to investigate the feeding habits of Oradarea sp. and $O$. walkeri, gut contents and lipid analyses suggested that $O$. edentata showed a high, year-round reliance on macroalgal tissues (Graeve et al. 2001). Joint use of gut contents, stable isotopes and fatty acid trophic markers highlighted that $O$. bidentata was also a primary consumer, and that it relied not only on macroalgae, but also on their epiphytic diatoms and endo/epiphytic filamentous algae (Aumack et al. 2017). The two Oradarea species studied here, whose guts mostly contained macroalgal fragments and/or diatom frustules, seem to have feeding habits that are comparable with their congeners. Interestingly, Oradarea sp. had specific grazing preferences. They fed avidly on $D$. menziesii, but did not consume Iridaea sp. This preferential consumption could be linked to the ability of red algae from the genus Iridaea to develop chemical defences against herbivores (Amsler et al. 1998). Oradarea bidentata was also found to have distinct dietary preferences when sampled in association with Desmarestiales or red algae (Aumack et al. 2017).
Aumack et al. (2017) analysed the gut contents of D. furcipes and found that the species ingested items similar to those we observed here (macroalgae, diatoms and crustacean parts), albeit in different proportions. This might indicate that some dietary plasticity exists in this species. Nevertheless, our gut contents results are consistent with this species mostly consuming living or recently dead macroalgal material (Aumack et al. 2017). Combined use of stable isotopes and fatty acid markers confirmed that $D$. furcipes held a low trophic position and mostly relied on macroalgae for its nutrition (Nyssen et al. 2005).

For feeding on live macrophytes and/or fresh macrophyte detritus, it is necessary to possess structures for biting off pieces of plant material and for grinding it prior to ingestion. The mandibles of Oradarea sp., $O$. walkeri and $D$. furcipes were very similar to one another and to those of other previously described herbivorous species (e.g. Mayer et al. 2009, Pavesi \& Olesen 2017), and all appear well-suited for this kind of feeding. All of these species have incisors with sharp dentition, which may facilitate cutting pieces from firm plant material (Mayer et al. 2009, Pavesi \& Olesen 2017). The left mandible of the three species also had a 
strong, sharply denticulate lacinia mobilis that probably works as an additional cutting edge (Coleman 1989b, Pavesi \& Olesen 2017). The setal row was well-developed and consisted of a range of numerous serrate and plumose setae in all three species. The molars of the three grazers, as with other herbivorous species, were structured like 'rasps' (i.e. ornamented with a dense concentration of strongly denticulate/spinous ridges; see Fig. 2e for Oradarea sp. molar details). This has been interpreted as a mechanism for triturating hard particles such as tough macroalgal tissues (Watling 1993, Momo et al. 1998, Mayer et al. 2009, Pavesi \& Olesen 2017).

\section{Suspension feeders}

The gut contents of $A$. richardsoni contained mostly planktonic items, notably diatoms (Dauby et al. 2001a, 2001b). Lipid markers suggested that phytoplanktonic organisms (including but not limited to diatoms) made up most of this species' diet (Graeve et al. 2001, Nyssen et al. 2005). Stable isotopes confirmed that this species occupied a low trophic position (2.1; Nyssen et al. 2002). Overall, A. richardsoni appeared to be a primary consumer relying mostly on the water column for its nutrition.

Generally speaking, denser setation of the mouthparts and other feeding-related appendages (antennae, gnathopods) has been linked to a greater trend towards filter-feeding (Caine 1974, 1977). Small particles in the water column are indeed collected passively or actively by setiferous antennae, which are cleaned by gnathopods and transferred to the mouthparts (Caine 1974, 1977). The setae row between the molar and the incisor is used to retain suspended organic matter collected from the surrounding water and is therefore well-developed in filter-feeders (Dixon \& Moore 1997, Poltermann 2001). In $A$. richardsoni, the two dense setae rows were composed of long serrate setae that join together when the mandible closes, thereby forming a kind of bridge between the tip of the mouthparts and the mouth itself. This appears particularly well-suited for retaining particles. Well-developed molar processes with blunt lamelliform cusps can be used to masticate hard materials such as diatom shells that may be present in marine snow (Caine 1974, Haro-Garay 2003). Ampelisca richardsoni possessed such well-developed and structured molars, although the ridges were fewer and blunter than what is usually observed in herbivorous species. This is consistent with the fact that smaller planktonic items require less processing prior to ingestion than tough algal tissues. On the other hand, the incisors of filter-feeders (A. richardsoni included), although similarly toothed, were less elongated and not as broad as the grazers' incisors, a trend that may be indicative of a reduced need for cutting.

\section{Generalist predators}

Feeding behaviour observations suggested that $E$. perdentatus acted as a 'sit-and-wait' passive predator (Klages \& Gutt 1990, Dauby et al. 2001a). Crustacean hard parts and pieces of polychaetes formed more than half of its gut contents, which also contained unidentifiable organic and inorganic material (Dauby et al. 2001a, 2001b). Stable isotopes confirmed the status of $E$. perdentatus as a predator, with a trophic position of 3.0 (Nyssen et al. 2005). It showed no particular specialization in terms of lipid or fatty acid compositions, suggesting that the species feeds on a wide range of items (Graeve et al. 2001, Nyssen et al. 2005). This was corroborated by the important variability of its carbon isotopic ratios (Nyssen et al. 2002). Overall, $E$. perdentatus seems to be a generalist predator, able to switch between dietary items (crustaceans, polychaetes), possibly according to food availability.

Wide and sharp, usually toothless ('axe-like') incisors with one broadened lacinia mobilis, columnar molars with a generally reduced triturative area and a lower number of small-sized setae have all been interpreted as adaptations to feeding on animal prey (Haro-Garay 2003). The mandibles of $E$. perdentatus showed these typical characteristics of predators. However, apart from these general trends, there seems to be a great degree of variation involved in the form of exclusively predatory mandibles, probably linked to prey nature and size (Watling 1993). Stout molars have also been associated with predatory habits (notably in opportunistic scavengers that also rely on active predation) and could be used to crush masses of soft food, such as decaying tissue, but also to break microzooplankton exoskeletons (Sainte-Marie 1984, Haro-Garay 2003). Predators' mandible morphology also appears to vary with the size of the animal, which reflects the prey size it can potentially exploit (Arndt et al. 2005). Wider incisors and taller molars with a more reduced triturative surface would occur in larger species/individuals (Haro-Garay 2003). Eusirus perdentatus, as one of the largest Antarctic amphipod species (up to $75 \mathrm{~mm}$ ), appeared to follow this trend. Some other opportunistic predators also present a toothed incisor, which may indicate that they feed on softer prey, such as gelatinous plankton, or could be indicative of a lower reliance on predation (i.e. an increased tendency to omnivory) (Haro-Garay 2003).

\section{Cnidarian predators/omnivores}

The gut content analyses of $E$. cf. similis specimens suggested that this species was a specialist predator of cnidarians (Dauby et al. 2001a, 2001b, Nyssen et al. 2002, 2005). Their stomach contents were indeed composed of $63 \%$ cnidarian remains on average, although other items such as sponge spicules, microalgae and pieces of 
polychaetes were also identified (Dauby et al. 2001a, 2001b). However, the presence of sediments in the guts of this species also suggested partial reliance on deposit feeding, and the fatty acid composition suggested assimilation of sediment-associated microorganisms (Nyssen et al. 2005). In addition, stable isotope analyses highlighted that this species relies on a broad spectrum of sources of organic matter (Nyssen et al. 2002, 2005).

Overall, insights from multiple methods suggest that $E$. cf. similis might be an omnivore rather than a strict cnidarian predator. Examination of its mandibles corroborated this view. Their morphology was indeed basic and showed no modifications that could be associated with a specialized regime. This is consistent with an omnivore having a broad prey spectrum. Mandibles were very similar to those of other omnivorous species (Arndt et al. 2005, Mayer et al. 2009, Mekhanikova 2010), which feature roughly toothed incisors and lacinia mobilis used to tear apart food items and a strong and ridged or rasp-like molar able to reduce food morsels to small pieces and crack and grind even hard plant material and diatom shells (Arndt et al. 2005). Conversely, mandibles of specialized cnidarian micropredators such as Maxilliphimedia longipes (Coleman 1989b), Andaniexis sp. or Stenothoe brevicornis (Moore et al. 1994) seem adapted to taking large bites of soft tissues and ingesting food as large, whole lumps. As such, the latter species bear an enlarged incisor cutting blade with very small or no teeth for cutting and slicing soft food, and when a molar is present, it is reduced or soft, without any grinding surface (Moore et al. 1994).

\section{Holothurian predators}

Stable isotopes suggested that the iphimediid I. cyclogena is a predator (trophic position: 3.7; Nyssen et al. 2002). Food items observed in its guts were mainly holothurian ossicles $(70 \%)$ and, to a lesser extent, polychaete remains and plankton (Nyssen et al. 2002). This led the authors to conclude that this species is a predator specializing in holothurians (De Broyer et al. 1999, Dauby et al. 2001a, Nyssen et al. 2002). Holothurians are a quite uncommon food source for invertebrates because their integument is strong and leathery, with embedded ossicles. Few amphipod species are known to feed on holothurians (Dauby et al. 2001a), and a single one was recognized to date as a specialized predator of this unusual prey, the Stilipedidae Alexandrella schellenbergi (previously Bathypanoploea schellenbergi; Coleman 1990).

The mouthparts of $A$. schellenbergi are highly adapted to cope with the tough tissues of these echinoderms (Coleman 1990). Its mandibles are remarkably stout, with strongly serrate incisors and left lacinia mobilis, providing three strong edges to cut through the firm body wall of holothurians (Coleman 1990). Although gut contents suggested that I. cyclogena mainly relied on the same food source as $A$. schellenbergi, its mandible morphology presents some notable differences (Fig. 3c \& d). Its mandibular body was more elongated, with much narrower incisors and a smooth lacinia mobilis on both sides. These differences could be explained by a change in the orientation of the cutting plane. Unlike A schellenbergi, which possesses transversely orientated incisors, the incisor of most iphimediids (including I. cyclogena) cuts in the vertical frontal plane (Watling \& Thurston 1989). The longitudinally orientated toothed cutting edge of the incisor of I. cyclogena (Fig. 3c \& d) accordingly suggested that it cuts in a scissor-like manner. Because of this change in orientation to offer a longer cutting edge, the incisor of I. cyclogena does not have to be wide, as in $A$. schellenbergi, but instead elongated. In both species, the molars were reduced and without any grinding surface, but the incisors presented many teeth. This suggests that the reduction of food to small pieces relies solely on the action of the incisors and lacinia mobilis (Coleman 1990).

\section{Scavengers}

The gut contents suggested that the diet of $U$. murrayi mostly consisted of carrion (Nyssen et al. 2002). Nevertheless, the guts of this species also contained crustacean and polychaete remains, and, when kept in tanks, this species could exhibit active predation behaviour (Dauby et al. 2001a). Similarly, in aquaria, P. carinata readily fed on any dead material provided, without preference, but crustacean remains could also be found in the guts of this species (Dauby et al. 2001a). Stable isotope ratios confirmed that these two species occupied high trophic positions (3.8 and 3.9, respectively), which is consistent with scavenging behaviour (Nyssen et al. 2002). Furthermore, their isotopic ratios were similar in terms of both carbon and nitrogen (Nyssen et al. 2002), suggesting they might rely on similar resources.

Many Lysianassoidea amphipods are highly mobile scavengers and have developed morphological, physiological and behavioural traits in relation to this lifestyle. Scavenging amphipods were previously classified into two distinct functional groups. The first is composed of voracious, rapid feeders, processing food in large bites that they swallow directly into the oesophagus. These usually larger species possess large and flexible guts and can survive long starvation periods (Steele \& Steele 1993, Seefeldt et al. 2017). Their mandibles are therefore adapted to take large bites of muscular food items. They have a bowl-shaped and enlarged mandibular body, a wide and sharp shearing incisor edge and a molar that is either non-triturative (similar to a 'setose tongue') or only bears a vestigial patch of triturative area (Dahl 1979, Sainte-Marie 1984). Such species' molars therefore do not have a grinding 
function, but can serve to push pieces of food into the stomodeum when the mandible is adducted (Steele \& Steele 1993). Members of the second functional group have a continuous and less rapid feeding behaviour and probably do not survive long starvation periods (Seefeldt et al. 2017). The mandibles of these usually smaller species bear a slender incisor process and a triturative molar (Sainte-Marie 1984, Momo et al. 1998, Arndt et al. 2005, Seefeldt et al. 2017). The development of the molar suggests that these animals rely on a broader dietary regime (Sainte-Marie 1984). This group would therefore be composed of more facultative scavengers that could also act as predators and/or deposit feeders (Seefeldt et al. 2017).

Here, both $U$. murrayi and $P$. carinata appeared to belong to this second functional group, as previous ecological studies suggested that they are also able to prey on live animals (Dauby et al. 2001a). Accordingly, they both displayed the typical mandible morphology of this group: a wide, smooth and sharp incisor combined with a triturative molar (Fig. $4 \mathrm{a} \&$ b).

\section{Conclusions}

For each of the nine Antarctic amphipod species presented here, mandible morphology seemed to be, to some extent, congruent with what is known of their feeding habits. This tends to confirm the links between mandible morphology and feeding strategies that were previously suggested for amphipods from other regions. These trends seem consistent across a wide variety of taxa and/or over large spatial scales, suggesting that mandible morphology can be a good descriptor of some aspects of trophic ecology. For example, differences in mouthpart morphology are usually seen between primary (herbivores and/or suspension feeders) and higher trophic level consumers (predators and/or scavengers). Similarly, mandible morphology can help us to discriminate between more generalist or specialist feeding strategies. The former are exemplified in this study by the case of $E$. cf. similis, for which the absence of mandible modifications that could be associated with a specialized diet seems consistent with findings from other methods classifying this species as an omnivore with a broad prey spectrum.

On the other hand, the links between mandible morphology and amphipod diet were seldom unambiguous or straightforward. Similar adaptations were found in distinct functional groups. For instance, grazers, suspension feeders and omnivores all showed very similar mandible morphologies that were close to the basic plan. Conversely, a great variability of mandible morphologies can also be found within the same functional group, as observed for generalist predators. Phenotypic plasticity is common in nutrition-related traits, and they may be independently lost or acquired over the course of evolution (Rüber et al. 1999). Phylogeny can therefore have an obfuscating effect on form-function relationships (Hutchins et al. 2014). In the case of $I$. cyclogena, a change in the orientation of the cutting plane during the evolution of iphimediids led to a very different mandible morphology from another unrelated species using the same food source, which can be misleading if phylogenetic effects are not taken into consideration. Finally, in some cases, dietary specialization can be linked with marked changes in the morphology of other mouthparts and/or accessory feeding appendages (e.g. antennae or gnathopods). For instance, the main characteristic of filter-feeders' mandibles, differentiating them from grazers or omnivores showing a similar basic morphology, is the increased setation, which is more visible on other feeding-related body parts than on the mandible (Cole \& Watkins 1977, Arndt et al. 2005, Mayer et al. 2009).

Overall, in many cases, mandible morphology on its own could not precisely predict amphipod feeding strategies. As with all trophic ecology methods, such as behavioural observations, gut content analyses or trophic markers, the mandible morphology examination possesses its own strengths and limitations. Nevertheless, when used in combination with some of the abovementioned methods, morphological observation of mouthparts proved to be able to complement them efficiently by shedding light on specific issues. As such, it could constitute a valuable source of information for integrative studies of amphipod ecological diversity in the Southern Ocean and beyond.

\section{Acknowledgements}

The authors would like to thank Prof W. Arntz (AWI, Bremerhaven) for his invitation to participate in the EASIZ cruises, the officers and crews of the RV Polarstern, AWI (Bremerhaven) colleagues who helped with collecting and sorting samples and Dr Claude De Broyer (RBINS, Brussels), who collected amphipod specimens from King George Island. Dr Y. Scailteur (RBINS) is acknowledged for his work on the gut content analyses. Particular thanks are given to Julien Cillis (RBINS) for his help with the scanning electron microscopy. LNM is indebted to Dr Laëtitia Leloup and Dr Jonathan Dedonder for facilitating the final steps of manuscript preparation. The authors also thank Dr Anna Jażdżewska and another anonymous reviewer whose comments helped improve this manuscript. This paper is contribution no. 42 to the vERSO project, contribution no. 18 to the RECTO project and MARE publication no. 397.

\section{Author contributions}

FLN and PD conceived the study. FLN performed the observations. FLN and LNM created the figures. FLN, 
LNM and MV interpreted the data. FLN and LNM prepared the manuscript with input from MV and PD.

\section{Financial support}

FLN was a Belgian Fund for Research Training in Industry and Agriculture (FRIA) grantee and a Belgian Funds for Scientific Research (F.R.S.-FNRS) postdoctoral researcher. LNM was an F.R.S.-FNRS research fellow and a Belgian Science Policy Office (BELSPO) postdoctoral researcher. MV is an F.R.S.-FNRS postdoctoral researcher. This research was performed under the auspices of the Scientific Research Programme on Antarctic (Phase IV) from the Belgian Federal Office for Scientific, Technical and Cultural Affairs (OSTC contract no. A4/36/BO2). It was also supported by BELSPO through the vERSO and RECTO projects (contract no. BR/132/A1/vERSO and BR/154/A1/RECTO).

\section{References}

Amsler, C.D., McClintock, J.B. \& BAKer, B.J. 1998. Chemical defense against herbivory in the Antarctic marine macroalgae Iridaea cordata and Phyllophora antarctica (Rhodophyceae). Journal of Phycology, 34, 10.1046/j.1529-8817.1998.340053.x.

Arndt, C.E., Berge, J. \& Brandt, A. 2005. Mouthpart-atlas of Arctic sympagic amphipods - trophic niche separation based on mouthpart morphology and feeding ecology. Journal of Crustacean Biology, 25, $10.1651 / \mathrm{C}-2544$.

Aumack, C.F., Lowe, A.T., Amsler, C.D., Amsler, M.O., McClintock, J.B. \& BAKER, B.J. 2017. Gut content, fatty acid, and stable isotope analyses reveal dietary sources of macroalgal-associated amphipods along the western Antarctic Peninsula. Polar Biology, 40, 10.1007/ s00300-016-2061-4.

CAINE, E.A. 1974. Comparative functional morphology of feeding in three species of caprellids (Crustacea, Amphipoda) from the northwestern Florida Gulf Coast. Journal of Experimental Marine Biology and Ecology, 15, 10.1016/0022-0981(74)90065-3.

CAINE, E.A. 1977. Feeding mechanisms and possible resource partitioning of the Caprellidae (Crustacea: Amphipoda) from Puget Sound, USA. Marine Biology, 42, 10.1007/BF00402195.

Cole, G.A. \& Watkins, R.L. 1977. Hyalella montezuma, a new species (Crustacea: Amphipoda) from Montezuma Well, Arizona. Hydrobiologia, 52, 10.1007/BF00036441.

Coleman, C.O. 1989a. Gnathiphimedia mandibularis K.H. Barnard 1930, an Antarctic amphipod (Acanthonotozomatidae, Crustacea) feeding on Bryozoa. Antarctic Science, 1, 10.1017/S0954102089000519.

Coleman, C.O. 1989b. On the nutrition of two Antarctic Acanthonotozomatidae (Crustacea: Amphipoda). Polar Biology, 9. 10.1007/BF00287425.

Coleman, C.O. 1990. Bathypanoploea schellenbergi Holman \& Watling, 1983, an Antarctic amphipod (Crustacea) feeding on Holothuroidea. Ophelia, 31, 10.1080/00785326.1990.10430862.

Coleman, C.O. 1991. Redescription of Anchiphimedia dorsalis (Crustacea, Amphipoda, Iphimediidae) from the Antarctic, and functional morphology of mouthparts. Zoologica Scripta, 20, 10.1111/j.1463-6409.1991.tb00301.x.

DAHL, E. 1979. Deep-sea carrion feeding amphipods: evolutionary patterns in niche adaptation. Oikos, 33, 10.2307/3543994.
DAHL, E. \& Hessler, R.R. 1982. The crustacean lacinia mobilis: a reconsideration of its origin, function and phylogenetic implications. Zoological Journal of the Linnean Society, 74, 10.1111/j.1096-3642. 1982.tb01145.x.

Dauby, P., Nyssen, F. \& De Broyer, C. 2003. Amphipods as food sources for higher trophic levels in the Southern Ocean: a synthesis. In HUISKES, A.H.L., Gieskes, W.W.C., Rozema, J., Schorno, S.M., van der Vies, S.M. \& WolfF, W.J., eds. Antarctic biology in a global context. Leiden: Backuys, 129-134.

Dauby, P., Scailteur, Y. \& De Broyer, C. 2001a. Trophic diversity within the eastern Weddell Sea amphipod community. Hydrobiologia, 443, 10.1023/A:1017596120422.

Dauby, P., Scailteur, Y., Chapelle, G. \& de Broyer, C. 2001b. Potential impact of the main benthic amphipods on the eastern Weddell Sea shelf ecosystem (Antarctica). Polar Biology, 24, 10.1007/s003000100265.

De Broyer, C. \& JAŻDŻewskA, A. 2014. Biogeographic patterns of Southern Ocean benthic Amphipods. In De Broyer, C., KoubBI, P., Griffiths, H.J., Raymond, B., D'Udekem d'Acoz, C., van de Putte, A.P., et al., eds. Biogeographic atlas of the Southern Ocean. Cambridge: Scientific Committee on Antarctic Research, 155-165.

De Broyer, C., Rauschert, M. \& Scailteur, Y. 1999. Structural and ecofunctional biodiversity of the benthic amphipod taxocoenoses. Berichte zur Polarforschung, 301, 163-174.

Dixon, I.M.T. \& Moore, P.G. 1997. A comparative study on the tubes and feeding behaviour of eight species of corophioid Amphipoda and their bearing on phylogenetic relationships within the Corophioidea. Philosophical Transactions of the Royal Society of London, B352, 10.1098/rstb.1997.0006.

Graeve, M., Dauby, P. \& Scailteur, Y. 2001. Combined lipid, fatty acid and digestive tract content analyses: a penetrating approach to estimate feeding modes of Antarctic amphipods. Polar Biology, 24, 10.1007/ s003000100295.

Guerra-García, J.M. \& Tierno de Figueroa, J.M. 2009. What do caprellids (Crustacea: Amphipoda) feed on? Marine Biology, 156, 10.1007/s00227-009-1220-3.

Haro-Garay, M.J. 2003. Diet and functional morphology of the mandible of two planktonic amphipods from the Strait of Georgia, British Columbia: Parathemisto pacifica (Stebbing, 1888) and Cyphocaris challengeri (Stebbing, 1888). Crustaceana, 76, 10.1163/ 156854003323009821.

Hutchins, B.T., Schwartz, B.F. \& Nowlin, W.H. 2014. Morphological and trophic specialization in a subterranean amphipod assemblage. Freshwater Biology, 59, 10.1111/fwb.12440.

Klages, M. \& GutT, J. 1990. Observations on the feeding behaviour of the Antarctic gammarid Eusirus perdentatus Chevreux, 1912 (Crustacea: Amphipoda) in aquaria. Polar Biology, 10, 10.1007/BF00237823.

Manton, S.M. 1977. The Arthropoda: habits, functional morphology, and evolution. Oxford: Clarendon Press, 577 pp.

Mayer, G., Haug, J.T., MaAs, A. \& Waloszek, D. 2013. Functional aspects of the gammaridean mandibles with special reference to the lacinia mobilis (Crustacea, Amphipoda). Zoologischer Anzeiger - A Journal of Comparative Zoology, 252, 10.1016/j.jcz.2012.11.007.

Mayer, G., Maier, G., Maas, A. \& Waloszek, D. 2009. Mouthpart morphology of Gammarus roeselii compared to a successful invader, Dikerogammarus villosus (Amphipoda). Journal of Crustacean Biology, 29, 10.1651/08-3056R.1.

Mekhanikova, I.V. 2010. Morphology of mandible and lateralia in six endemic amphipods (Amphipoda, Gammaridea) from Lake Baikal, in relation to feeding. Crustaceana, 83, 10.1163/001121610X504289.

Momo, F., Bogazzi, E. \& Duttweiler, F. 1998. Amphipods of Potter Cove: community composition, biology and growth. Berichte zur Polar- und Meeresforschung, 299, 144-149.

Moore, P.G., Rainbow, P.S. \& Vader, W. 1994. On the feeding and comparative biology of iron in coelenterate-associated 
gammaridean Amphipoda (Crustacea) from N. Norway. Journal of Experimental Marine Biology and Ecology, 178, 10.1016/0022-0981 (94) $90037-X$

Nyssen, F., Brey, T., Dauby, P. \& Graeve, M. 2005. Trophic position of Antarctic amphipods - enhanced analysis by a 2-dimensional biomarker assay. Marine Ecology - Progress Series, 300, 10.3354/ meps300135.

Nyssen, F., Brey, T., Lepoint, G., Bouquegneau, J.M., de Broyer, C. \& Dauby, P. 2002. A stable isotope approach to the eastern Weddell Sea trophic web: focus on benthic amphipods. Polar Biology, 25, 10.1007/s00300-001-0340-0.

PAVesi, L. \& Olesen, J. 2017. Functional morphology and environmental adaptations of mouthparts in the driftwood amphipod Macarorchestia remyi (Schellenberg, 1950), and a comparison with the sandhopper Talitrus saltator (Montagu, 1808) (Amphipoda: Talitridae). Journal of Crustacean Biology, 37, 10.1093/jcbiol/ruw006.

Poltermann, M. 2001. Arctic sea ice as feeding ground for amphipods food sources and strategies. Polar Biology, 24, 10.1007/s003000000177.

Rüber, L., Verheyen, E. \& Meyer, A. 1999. Replicated evolution of trophic specializations in an endemic cichlid fish lineage from Lake
Tanganyika. Proceedings of the National Academy of Sciences of the United States of America, 96, 10.1073/pnas.96.18.10230.

Sainte-Marie, B. 1984. Morphological adaptations for carrion feeding in four species of littoral or circalittoral lysianassid amphipods. Canadian Journal of Zoology, 62, 10.1139/z84-244.

Seefeldt, M.A., Campana, G.L., Deregibus, D., Quartino, M.L., Abele, D., Tollrian, R. \& Held, C. 2017. Different feeding strategies in Antarctic scavenging amphipods and their implications for colonisation success in times of retreating glaciers. Frontiers in Zoology, 14, 10.1186/s12983-017-0248-3.

Steele, D.H. \& Steele, V.J. 1993. Biting mechanism of the amphipod Anonyx (Crustacea: Amphipoda: Lysianassoidea). Journal of Natural History, 27, 10.1080/00222939300770521.

WatLING, L. 1993. Functional morphology of the amphipod mandible. Journal of Natural History, 27, 10.1080/00222939300770511.

Watling, L. \& Thurston, M.H. 1989. Antarctica as an evolutionary incubator: evidence from the cladistic 415 biogeography of the amphipod family Iphimediidae. In Crame, J.A., ed. Origins and evolution of the Antarctic biota. Special Publication of the Geological Society of London, No. 47, 297-313. 